\title{
Ammonia Recovery from Wastewaters by Adsorption with subsequent Transmembrane Chemical Absorption
}

\author{
Tatiana Samarina, Esther Takaluoma \\ Kajaani University of Applied Sciences \\ Ketunpolku 1, PL 52, 87101, Kajaani, Finland \\ tatiana.samarina@kamk.fi; esther.takaluoma@kamk.fi
}

\section{Extended Abstract}

Nutrient recovery from urban and industrial waste streams is an emerging trend [1]. More and more technologies proposed have been demonstrated recently not at laboratory scale but small-scale pilotings or as pre-industrial demonstrations. Moreover, if for phosphorous recovery a wide variety of layouts are presented in the literature [2], for nitrogen only fragmented or small-scale demonstrations have been reported [3].

Widely, only removal (not recovery) of ammonium nitrogen by deaerating, aerobic treatment, or ANAMMOX process is applied at municipal and industrial sites. Membrane technology is a growing alternative specifically for ammonia recovery from wastewaters [4]. However, membrane technology has some demerits such as high-energy consumption, sensitivity of the membrane contactor to content of suspended solids, or scaling up problems to accept massive stream sizes. As merits in comparison to other physical water treatment processes such as air-stripping or evaporation/distillation are extremely high selectivity towards target substance, uncomplicated installation, and an ability to recover minor but valuable components. Among the available alternatives, the transmembrane chemical absorption (TMCA) has been gaining consideration, especially under certain operating conditions [5], [6]. TMCA using a membrane contactor is a unique separation process that is transitioning from research and pilot phases to field installations. Work published recently [7] is presenting ammonium recovery from waters with high ammonium content ( $>400 \mathrm{mg} / \mathrm{L})$. The main aim of this research is to demonstrate for the first time recovery of ammonium nitrogen from diluted solutions (WWTP or mine wastewaters). Consumption of chemicals is the largest expense in a TMCA process [6], since the dissolved ammonium ions must be converted to free ammonia gas by $\mathrm{pH}$ adjustment of feed phase in order to remove ammonia from a wastewater stream.

This paper presents the results of an ammonia recovery system using $3 \mathrm{M}$ Liqui-Cel ${ }^{\circledR}$ membrane contactor with preceding ammonium concentration on inorganic polymers (geopolymers, GPs). The procedures of GPs preparations were reported earlier [8], [9]. Those adsorbents were used for removal of ammonium nitrogen from municipal wastewater after secondary treatment stage. Liquid phase obtained during adsorbent regeneration were purified in Liqui-Cel membrane contactor in order to recovery ammonium nitrogen as ammonium sulfate or phosphate. Purified regeneration solution was used repeatedly for further adsorbent regeneration. Several regeneration-purification cycles were conducted to estimate system sustainability and chemical consumption demand. Operational conditions of TMCA process such as shellside and lumenside feed steams, temperature, and $\mathrm{pH}$ were adjusted to gain maximal capacity of the setup. One contactor $2.5 \times 8$ inch Liqui-Cel ${ }^{\circledR}$ membrane were used under following operational conditions: $100 \mathrm{~L} / \mathrm{h}$ shellside and $60 \mathrm{~L} / \mathrm{h}$ lumenside feed steams, $40^{\circ} \mathrm{C}$ working temperature, $\mathrm{pH} \geq 10$. Technical sulfuric or phosphoric acids, up to $5 \%$, were used as lumenside steam. The concentration of ammonium-content salt in a resulting received phase were from $17 \%$ and $22 \%$ for phosphate and sulfate salt, respectively.

Technical analysis showed that adsorption followed by Liqui-Cel® membrane could be used for ammonium nitrogen recovery from municipal wastewater with reasonable cost. The proposed approach has low footprint and energy demand, and utilizes industrial side-streams as raw material in production cycle.

This study was conducted as part of the WaterPro project (number A74635 EAKR, Keski-Pohjanmaan Liitto/Kainuun Liitto/Pohjois-Pohjanmaan liitto) with the support of Maa- ja vesitekniikan tuki (№ 13-8271-17). 


\section{References}

[1] J. M. Lema and S. S. Martinez, Innovative Wastewater Treatment \& Resource Recovery Technologies: Impacts on Energy, Economy and Environment. London, IWA: IWA Publishing, 2017.

[2] L. Egle, O. Zoboli, A. Amann, J. Krampe, H. Rechberger, and M. Zessner, "Comparison of technologies for phosphorus recovery - Identification of an ideal solution?," in Phosphorus: Polluter and Resource of the Future Removal and Recovery from Wastewater, C. Schaum, Ed. International Water Association: IWA Publishing, 2018, pp. 455-486.

[3] Y. Ye, H.H. Ngo, W. Guo, Y. Liu, S.W. Chang, D.D. Nguyen, H. Liang, J. Wang, “A critical review on ammonium recovery from wastewater for sustainable wastewater management," Bioresour. Technol., vol. 268, pp. 749-758, 2018.

[4] M. Darestani, V. Haigh, S. J. Couperthwaite, G. J. Millar, and L. D. Nghiem, "Hollow fibre membrane contactors for ammonia recovery: Current status and future developments," J. Environ. Chem. Eng., vol. 5, no. 2, pp. 1349-1359, 2017.

[5] A. Hasanoğlu, J. Romero, B. Pérez, and A. Plaza, "Ammonia removal from wastewater streams through membrane contactors: Experimental and theoretical analysis of operation parameters and configuration," Chem. Eng. J., vol. 160, no. 2 , pp. $530-537,2010$.

[6] M. Ulbricht, J. Schneider, M. Stasiak, and A. Sengupta, "Ammonia Recovery from Industrial Wastewater by TransMembraneChemiSorption," Chem. Ing. Tech., vol. 85, no. 8, pp. 1259-1262, 2013.

[7] M. Ulbricht, G. Lakner, J. Lakner, and K. Belafi-Bako, "TransMembraneChemiSorption of ammonia from sealing water in Hungarian powder metallurgy furnace," Desaline. Water Treat., vol. 75, pp. 253-259, 2017.

[8] T. Luukkonen, K. Věžníková, E.-T. Tolonen, H. Runtti, J. Yliniemi, T. Hu, K. Kemppainen, U. Lassi, "Removal of ammonium from municipal wastewater with powdered and granulated metakaolin geopolymer," Environ. Technol., vol. 39, no. 4, pp. 414-423, 2018.

[9] T. Samarina and E. Takaluoma, "Metakaolin-Based Geopolymers for Removal of Ammonium from Municipal Wastewater," in Proceedings of The 5th World Congress on New Technologies, Lisbon, 2019, pp. 195-1 - 195-5. doi: 10.11159/icepr19.195. 